\title{
SUBSTANTIATION AND DIFFERENTIAL APPROACH TO OPERATIVE TREATMENT OF PATIENTS WITH PSORIATIC ARTHRITIS
}

D0I: $10.36740 /$ WLek202001110

\author{
Olexandr A. Burianov, Volodymyr P. Kvasha, Yuriy L. Sobolevskiy, Roman L. Stepanenko \\ BOGOMOLETS NATIONAL MEDICAL UNIVERSITY, KYIV, UKRAINE
}

\begin{abstract}
The aim: To improve the psoriatic arthritis treatment outcomes by establishing and implementing into practice operative treatment.

Materials and methods: The study basis is represented with the results of examination and treatment of 252 patients with psoriatic arthritis. The biopsy samples from the problem psoriatic eruption and intact skins regions, received from 74 patients, were studied.

Results: The study has established presence of Staphylococcus aureus in affected skin regions. The authors present their classification of structural muscular-skeletal disorders associated with psoriatic arthritis, which will substantiate the volume and character of operative interventions.

Conclusions: Detection of numerous opportunistic pathogenic microorganism colonies stipulates for the necessary skin debridement while planning further operative treatment, aimed at correction of anatomical and biological abnormalities. The operative intervention volume depends on the severity of structural dysfunctions.
\end{abstract}

KEY WORDS: psoriatic arthritis, operative treatment

\section{INTRODUCTION}

Psoriatic arthritis is an independent nosological type of non-specific general disorder of muscular-skeletal system associated with psoriasis. The disease has multifactorial genesis with hereditary predisposition and is characterized by chronic progressive recurring development which leads to continuous and permanent disability of the patients.

Psoriatic arthritis (PA) affects from $5 \%$ to $60 \%$ of patients with psoriasis $(\mathrm{P})$, more often men. The disease may develop at any age, but it most often affects the working age population (from 30 to 50 years), so the question of prevention and treatment of muscular-skeletal dysfunctions associated with psoriasis, particularly at its early stage, is medically and socially urgent [1-5].

Such statistical difference may be explained by different places of residence, though, in our mind, it is related to some drawbacks of the condition diagnostics [6]

Despite considerable achievements in the disease etiology and pathogenesis study, many questions are still unclear. The basic causing factors of the disease are: heredity; immune diseases, disordered mineral metabolism and connective tissue metabolism, chronic infection foci, various diseases affecting other organs, psychoasthenic and neuropathic conditions, negative effect of the environment (temperature, radiation, etc.), injuries and traumas [7-10 ].

Within this context, PA should be considered as a process with multifactorial nature and pathological changes related to the additional action of hereditary and environmental factors [1].

Modern conservative treatment of psoriatic arthritis using the newest and traditional medications provides for significant improvement in the patients' condition [11-13].
Though, it is necessary to mention that with considerable structural and functional dysfunctions in any region of the muscular-skeletal system, the medication therapy effectiveness is minimum, or, to say directly, ineffective. There are single reports about operative treatment of such patients, based on several cases, which cannot evidence about the indications and contraindications to it [14].

So, the PA in modern orthopedics represents an urgent problem, as etiology and pathogenesis of this process haven't been defined completely as well as the methods of diagnostics, complex orthopedic prevention and treatment, which decreases the specialized treatment quality for such patients.

\section{THE AIM}

To improve the psoriatic arthritis treatment outcomes by establishing and implementing into practice operative treatment.

\section{MATERIALS AND METHODS}

The complex examination included clinical, general laboratory, immunological, biochemical, roentgenological, sonographical, densitometrical, arthroscopic and morphological study methods.

The study represents the results of examination and treatment of 252 patients with PA of various active stages, spread and severity. 82 patients have undergone operative treatment.

The authors have also studied 74 patients with progressing psoriasis vulgaris, moderate or severe dermatosis. The 
Table I. Groups of patients by age, age period of disease onset and disease duration.

\begin{tabular}{|c|c|c|c|c|c|c|c|c|}
\hline \multirow{2}{*}{$\begin{array}{l}\text { Age of the patients } \\
\text { (years old) }\end{array}$} & \multirow{2}{*}{ Amount } & \multirow{2}{*}{$\%$} & \multicolumn{3}{|c|}{ Age period of the disease onset } & \multicolumn{3}{|c|}{ Duration of the disease } \\
\hline & & & Years old & amount & $\%$ & years & amount & $\%$ \\
\hline $21-30$ & 17 & $\begin{array}{c}6.7 \\
166\end{array}$ & Less than 20 & $\begin{array}{l}25 \\
59\end{array}$ & 10.0 & Less than 10 & 123 & 48.8 \\
\hline $31-40$ & 42 & 16.6 & $21-30$ & $\begin{array}{l}59 \\
75\end{array}$ & 23.3 & $11-20$ & 92 & 36.6 \\
\hline $41-50$ & 67 & 26.7 & $31-40$ & $\begin{array}{l}75 \\
59\end{array}$ & 30.0 & $21-30$ & 17 & 6.7 \\
\hline $51-60$ & 67 & 26.7 & $41-50$ & $\begin{array}{l}59 \\
31\end{array}$ & 23.3 & $31-40$ & 17 & 6.7 \\
\hline 61 and more & 59 & 23.3 & $51-60$ & 34 & 13.4 & $41-50$ & 3 & 1.2 \\
\hline Totally & 252 & 100 & & 252 & 100 & & 252 & 100 \\
\hline
\end{tabular}

Table II. Incidence of the muscular-skeletal disorders related to localization

\begin{tabular}{cc}
\hline Localization & Incidence, $\%$ \\
\hline Shoulder joints & 12.6 \\
\hline Elbow joints & 27.2 \\
\hline Radial wrist joints & 10.2 \\
\hline Digital hand joints & 74.7 \\
\hline Kульшові cyглоби & 13.4 \\
\hline Iliosacral joints & 53.2 \\
\hline Pelvic joint & 58.2 \\
\hline Ankle foot joint & 29.7 \\
\hline Metatarsophalangeal and interphalangeal foot joints & 64.7 \\
\hline Psoriatic spondyloarthritis & 21.6 \\
\hline Pubic symphysis & 14.2 \\
\hline
\end{tabular}

Table III. Structural dysfunctions of the muscular-skeletal system with associated with psoriatic arthritis

\begin{tabular}{|c|c|c|c|c|}
\hline \multirow{2}{*}{ Roentgenological signs } & \multicolumn{4}{|c|}{ Stage } \\
\hline & $\mathbf{I}$ & II & III & IV \\
\hline Increased rate and loss of the periarticular tissue structure & + & ++ & ++ & +++ \\
\hline Osteoporosis & + & ++ & +++ & ++- \\
\hline Narrowing of the joint space ( \% ) & Less than 25 & $25-50$ & $50-75$ & $>75$ \\
\hline Destruction of the arch laminae & + & ++ & +++ & ++- \\
\hline Destruction of the joint surface ( \% ) & - & Less than 25 & $25-50$ & $>50$ \\
\hline Congruency disorders (dislocation, subluxation) & - & + & ++ & +++ \\
\hline Ankyloses / Lysis & - & - & +- & ++ \\
\hline
\end{tabular}

age of the patients ranged from 18 to 73 years, with 32 (43.24\%) females, and 41 (56.76\%) males. Morphological and immune-histological biopsy samples were taken from the psoriatic eruption and intact skin regions to detect structure changes and microorganism colonies characteristics, according to the defined antigenic properties. The skin biopsy fragments were treated by $10 \%$ neutral formaline. Further, the biopsy material was treated with spirit to be introduced in paraffin blocks, from which histological sections $4-6 \mathrm{mcm}$ in width were prepared.

The obtained histological preparations were studied using the "Olympus BX 51" microscope, „Olympus C 5050 Z" digital camera and "Olympus DP-Soft" software.

To compare the results of appropriate morphological and immunohistochemical studies the authors studied biopsy samples taken from the anterior abdominal wall skin in almost healthy patients (5 patients).

\section{RESULTS AND DISCUSSION}

The performed morphological and immunohistochemical studies of skin biopsy samples taken from the skin psoriatic eruption regions revealed general inflammatory infiltration in epidermis and dermis layers as well as numerous germ colonies under the stratum corneum in $49(66.21 \%)$ from 74 patients with psoriasis. Also, 19 (25.67\%) patients had germ colonies under the stratum corneum in their biopsy samples taken from the intact skin regions. Altogether, 


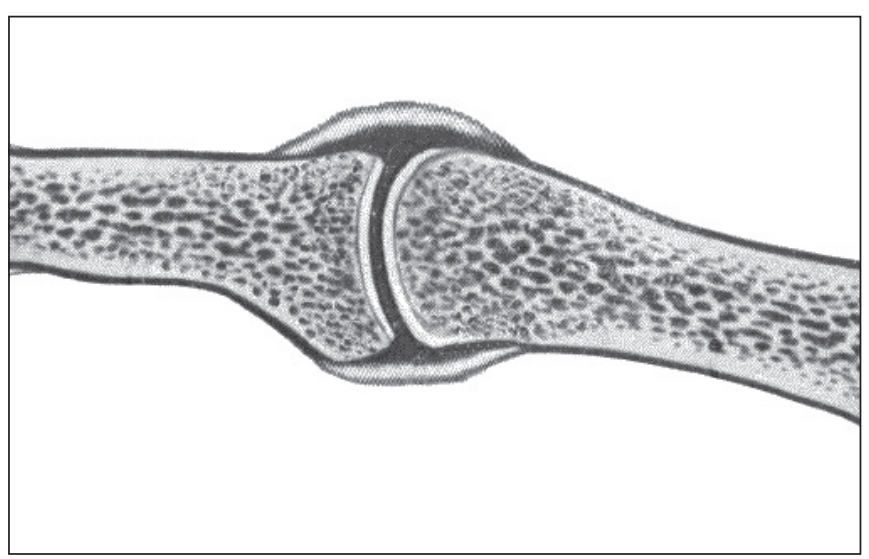

Fig. 1. Stage 1 (own figure).

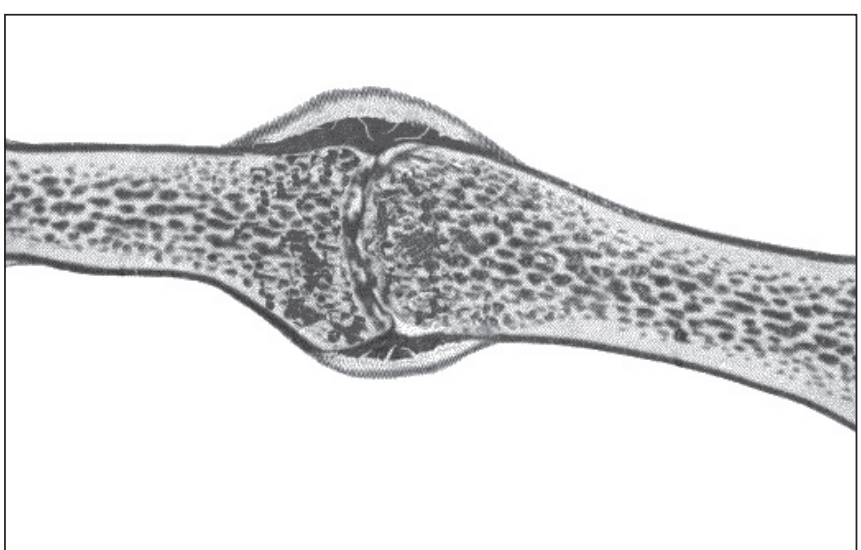

Fig. 3. Stage 3 (own figure).

the number of the detected microorganism colonies in the intact skin regions was considerably lower than that one in the skin psoriatic eruption regions. The general infiltration in the epidermis and dermis layers in the appropriate biopsy samples taken from the intact skin regions was absent.

The immunohistochemical trials were conducted, in order to establish the species composition of microorganism colonies which were detected under the stratum corneum in skin biopsy samples taken from the skin psoriatic eruption regions and intact skin of patients with psoriasis, and they showed that the appropriate microorganisms belong to Staphylococcus aureus species.

Examination of 25 (33.79\%) from 74 examined patients with psoriasis didn't reveal present microorganism colonies under the stratum corneum in the biopsy samples taken from the skin psoriatic eruption and intact skin regions. The biopsy material taken from the anterior abdominal wall skin of the control group patients ( 5 almost healthy patients) didn't show microorganism colonies under the stratum corneum as well.

Totally the study includes 252 patients with PA, 147 (58.3 $\%)$ males and 105 (41.7\%) females, which corresponds to 3:2 ratio. The grouping of patients according to the age, age period of the disease onset and disease duration are represented in table $\mathrm{I}$.

The dysfunctions of muscular-skeletal system associated with PA most often appear within 1-3 years after the first

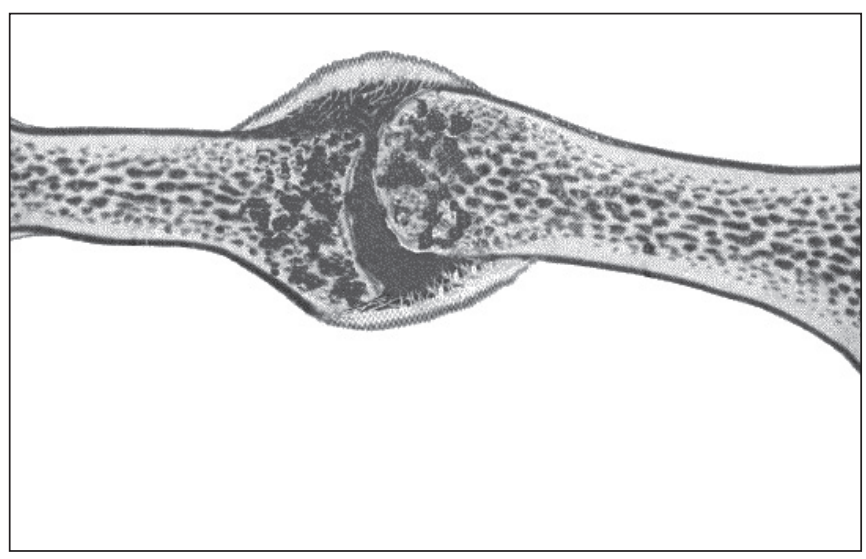

Fig. 2. Stage 2 (own figure).

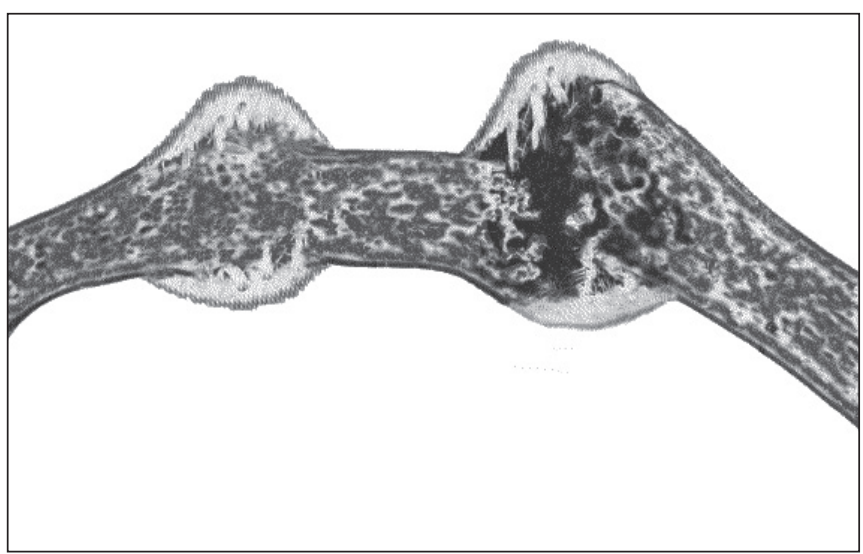

Fig. 4. Stage 4 (own figure).

manifestations of psoriasis ( $38.45 \%)$ and at the age period from 10 to 30 years $(28.85 \%)$.

The most common muscular-skeletal dysfunction associated with PS is polyarthritis, which was diagnosed in $87.3 \%$ of all cases (220 patients), respectively mono- and oligo-arthritis in $12.7 \%$ of all cases (32 patients).

The data incidence of muscular-skeletal disorders according to localization are represented in table II.

Most often the muscular-skeletal disorders appear with psoriasis after the skin manifestations (79.76\%), though they may precede them (4.76\%) or develop simultaneously (15.48\%).

The obtained roentgenological signs were grouped into the early and late ones. The early roentgenological manifestations of the PA are:

- its pronounced rate, affected structure, thickening of periarticular tissues;

- irregular narrowing of joint space;

- osteoporosis within the bone epimetaphyses;

- edge resorption of the hand and foot distal phalanges tuberosities (usuras).

The late roentgenological signs are:

- irregularity, thinning, disintegration of the joint surface end plates;

- linear periosteal layering in the hand and foot phalanges;

- focal or bone-like destruction and lysis of the epimetaphyses, which further lead to destructive dislocations and semi-dislocations;

- ankyloses 
Table IV. Operative interventions according to the structural-functional dysfunctions

\begin{tabular}{ccccc}
\hline \multirow{2}{*}{$\begin{array}{c}\text { Structural-functional } \\
\text { dysfunction stage }\end{array}$} & \multicolumn{4}{c}{ Operative intervention methods } \\
\cline { 2 - 5 } & Synovocapsulectomy. Tenoplasty & Arthroplasty & Endoprosthetics & Bone autoplasty \\
\hline I & 23 & - & - & - \\
\hline II & 11 & - & - & - \\
\hline III & 8 & 4 & - & - \\
\hline IV & - & 3 & 31 & 2 \\
\hline Totally & 42 & 7 & 31 & 2 \\
\hline
\end{tabular}

Table V. Results of operative treatment according to the structural-functional dysfunction degree.

\begin{tabular}{cccc}
\hline \multirow{2}{*}{ Structural-functional dysfunction stage } & \multicolumn{3}{c}{ Treatment outcomes (\%) } \\
\cline { 2 - 4 } & Good & Satisfactory & Unsatisfactory \\
\hline Stage 1 & 95.7 & 4.3 & - \\
\hline Stage 2 & 92.2 & 7.8 & - \\
\hline Stage 3 & 76.3 & 18.5 & 5.2 \\
\hline Stage 4 & 68.1 & 20.1 & 11.8 \\
\hline
\end{tabular}

Due to the complex and comparative analysis of the received results by the above-mentioned methods the authors have classified structural dysfunctions of muscular-skeletal system associated with psoriatic arthritis, the classification represented in table III.

The scheme of the offered classification is represented in figures: figure 1- stage 1; figure 2 - stage 2; figure 3 stage 3: figure 4 - stage 4.

According to the above mentioned classification, the patients were divided into the clinical groups:

Group 1 - patients with initial lesions, the $1^{\text {st }}$ stage of the muscular-skeletal structural disorders, the process activity: $1-2$, joint insufficiency degree: $0-1$. Such patients with absent deformities showed slight exudative-proliferative changes and initial muscular atrophy stage.

Group 2 - patients with initial and slight deformities, second stage of the muscular-skeletal system disorders, process activity: 1-2, joint insufficiency degree: 1-2.

Group 3 - patients with significant deformities, stage of structural muscular-skeletal system disorders, process activity: 1-2, joint insufficiency degree: 2-3.

Group 4 - severe deformities, ankyloses and lysis, significant function loss, stage 4 of the muscular-skeletal system structure disorders, process activity: 1-2, joint insufficiency degree -3 .

According to the distribution of the patients into the above mentioned groups, appropriate operative interventions were conducted (table IV).

The results of operative treatment, conducted according to the degree of structural-functional disorders, are represented in table $\mathrm{V}$. The analysis of the long-term outcomes of operative treatment showed their high efficiency. In patients with early stage synovectomies should be emphasized, conducted in the "classical" and arthroscopic ways. Synovectomies should be regarded as both treatment and prevention: excision of the pathologically changed syno- vial membrane decreases autosensibilization, improves trophics of the cartilage, which prevents severe destruction of the cartilage and epimetaphyses. Alongside, after such interventions we observe skin manifestations regress, prolonged remission and improvement of the patients general condition, which is confirmed by the laboratory data stabilization. High efficiency of synovectomies was observed in group 1 and 2 of the patients with subacute and chronic inflammations.

Correcting osteotomies and endoprosthetics were conducted in group 4, and the analysis of long-term outcomes evidences about significant benefits of endoprosthetics.

\section{CONCLUSIONS}

1.Presence of numerous colonies of opportunistic microorganisms Staphyloccocus aureus under the stratum corneum in psoriatic skin eruption regions in most psoriasis patients with progressing dermatosis as well as the presence of these colonies under the stratum corneum of intact skin in some patients stipulates for the necessary skin debridement when planning operative treatment.

2. Complex pathogenetic treatment of patients with PA must include operative orthopedic interventions aimed at restoration of anatomical-biochemical dysfunctions of the muscular-skeletal system. Synovectomies and capsulosynovectomies represent the most effective treatment measures of treatment and prevention in patients of the $1^{\text {st }}$ and $2^{\text {nd }}$ clinical groups.

3. According to the conducted studies, the differential approach to operative treatment of patients with PA was elaborated, the approach considering the stage, form and spread of pathological process. Pre-operative preparation of the patients is of significant importance, as it must be pathogenetically determined and individualized. 


\section{REFERENCES}

1. Burianov 0.A., Kvasha V.P. Psoriatic arthritis: questions of genesis, diagnosis, treatment. LTD «Lenvit», Kyiv. 2009, p 202

2. Zacharie H. Prevalence of joint disease in patients with psoriasis: implications for therapy. Am J ClinDermatol. 2003;4:441.

3. Gelfand JM, Gladman DD, Mease PJ, et al. Epidemiology of psoriatic arthritis in the population of the United States. J Am Acad Dermatol. 2005;53:573.

4. Tam LS, Leung YY, Li EK 30. Tam LS, Leung YY, Li EK. Psoriatic arthritis in Asia. Rheumatology (0xford). 2009;48(12):1473-7.

5. Yang Q, Qu L, Tian H, et al. Prevalence and characteristics of psoriatic arthritis in Chinese patients with psoriasis. J Eur Acad Dermatol Venereol. 2011;25(12):1409-14.

6. Rudwaleit M, Taylor WJ. Classification criteria for psoriatic arthritis and ankylosing spondylitis/axial spondyloarthritis. Bailliere's Best Pract Res Clin Rheumatol. 2010;24:589-604.

7. Parisi R, Symmons DP, Griffi ths CE, Ashcroft DM. Identification and Management of Psoriasis and Associated Comorbidity (IMPACT) project team. Global epidemiology of psoriasis: a systematic review of incidence and prevalence. J Invest Dermatol. 2013;133(2):377-85.

8. Griffi ths CE, Barker JN. Pathogenesis41. Wolk K, Witte E, Warszawska K, Schulze-Tanzil G, Witte K, Philipp S, et al. The Th17 cytokine IL-22 induces IL-20 production in keratinocytes: a novel immunological cascade with potential relevance in psoriasis. Eur J Immunol. 2009;39(12):3570-81.

9. Duhen T, Geiger R, Jarrossay D, Lanzavecchia A, Sallusto F. Production of interleukin 22 but not interleukin 17 by a subset of human skin-homing memory T cells. Nat Immunol. 2009;10(8):857-63.
10. Fujita H. The role of IL-22 and Th22 cells in human skin diseases. J Dermatol Sci. 2013;72(1):3-8.

11. Coates LC, Kavanaugh A, Mease P, et al. Group for research and assessment of psoriasis and psoriatic arthritis: treatment recommendations for psoriatic arthritis 2015. Arthritis Rheum. 2015 (submitted).

12. Baranauskaite A, Raffayova $H$, Kungurov NV, et al. Infliximab plus methotrexate is superior to methotrexate alone in the treatment of psoriatic arthritis in methotrexate- naive patients: the RESPOND study. Ann Rheum Dis. 2012;71(4):541-8.

13. Coates LC, Navarro-Coy N, Brown SR, et al. The TICOPA protocol (Tlght COntrol of Psoriatic Arthritis): a randomised controlled trial to compare intensive management versus standard care in early psoriatic arthritis. BMC Musculoskelet Disord. 2013;14:101

14. Brekhov A.N., Prytula O.A., Fedulicheva E.A., Krutykov D.S. Mikrodysektomiia pry psoriaticheskom spondiloartroze. Litopys trovmatologii ta ortopedii. 2003;1-2:24 - 27

\section{ORCID and contributionship:}

Olexandr A. Burianov - 0000-0002-2174-1882 ${ }^{A, E}$

Volodymyr P. Kvasha - 0000-0002-7444-6289 B,C,D

Yuriy L. Sobolevskiy - 0000-0002-8690-8620 C,D,F

Roman L. Stepanenko - 0000-0001-8423-0388 ${ }^{\mathrm{A}}$

\section{Conflict of interest:}

The Authors declare no conflict of interest

\section{CORRESPONDING AUTHOR Olexandr A. Burianov}

Department of Traumatology and Orthopedics,

Bogomolets National Medical University,

13, T. Shevchenka Blvd, 01601, Kyiv, Ukraine

tel: +380442880126

e-mail: kaftraum@ukr.net

Received: 16.04 .2019

Accepted: 01.11.2019

A - Work concept and design, B - Data collection and analysis, C - Responsibility for statistical analysis,

D-Writing the article, $\mathbf{E}$-Critical review, $\mathbf{F}$ - Final approval of the article 